\title{
EDDY CURRENT EXAMINATION OF CARBON FIBRES IN CARBON-EPOXY COMPOSITES AND KEVLAR
}

\author{
R. Grimberg ${ }^{1}$, A. Savin ${ }^{1}$, R. Steigmann ${ }^{1}$, A. Bruma ${ }^{2}$ \\ ${ }^{1}$ National Institute of Research and Development for Technical Physics, Iasi, Romania \\ ${ }^{2}$ Al.I Cuza University, Iasi, Romania
}

\begin{abstract}
This paper proposes a special eddy current transducer, send receive type and a holographic method for signal processing, able to emphasize the delaminations and massive breaking zones in carbon fibres. To evaluate individual fibres breaking, a eddy current microscopy method is proposed.
\end{abstract}

Keywords: Carbon fibres, Carbon epoxy composites, Kevlar, Eddy current examination, Eddy current holography, Eddy current microscopy

\section{Introduction}

Given their specific characteristic, the carbon-epoxy composites are used in different application, from airspace industry to sporting goods. As compared to the metallic materials, carbon epoxy composites show a series of advantages, among which a high tensile strength, low density and coefficient of thermal expansion, absence of phenomena specific to the fatigue state, possibility of a relative simple manufacturing of large layered structures. The carbon epoxy composites exhibit electric properties that depend on the type of used carbon fibres and on their volume fraction in the materials, having the transverse electric conductivity between 10 and $100 \mathrm{~S} / \mathrm{m}$ and longitudinal conductivity ranging between $5^{*} 10^{3}$ and $5^{*} 10^{4} \mathrm{~S} / \mathrm{m}$.

In the case of low energy impacts, the composite gets elastically deformed and a local alteration of the electric conductivity occurs. For high energy impacts, the local deformation results in delaminating, deviation or breaking of the carbon fibres.

As the carbon fibres, the KEVLAR fibres have different applications, considering the fact that it is 5 time stronger than steel. It is used in bullet-proof jacket worn by Special Forces, Police, etc. The Kevlar body armour has the capability to stop a bullet fired from a 0.45 calibre gun but rarely stops anything more powerful as, for example, a bullet of $7.62 \mathrm{~mm}$ which is fired from a AK 47 assault riffle.

The Kevlar is a poly (p-phenylenterephtalamide) having an electric conductivity between $10^{-10}$ and $10^{-14} \mathrm{~S} / \mathrm{m}$.

At impact with low energy (bullets with small calibre or large distance till target), the fibers that form the texture are open up, and, together with the elasticity of fibres, and these processes absorb the energy of the bullet. At impacts with high energy, the bullet penetrates the first layers 
that can be locally heated at temperatures higher than $400^{\circ} \mathrm{C}$, at which local thermal damage, with conductive carbon deposition appears [1].

From here results that the both types of material, so carbon epoxy as well as Kevlar that can be used as texture or as reinforcement fibres in epoxy resin can be nondestructive evaluated using electromagnetic methods [2], [3], [4]. Usually, especial in the case of composites Kevlar-epoxy, the standard methods of nondestructive evaluation are laser ultrasonic and infrared thermography [5].

In this paper is presented a new type of eddy current focused transducers that allows the visualisation of distribution and state of carbon fibres from carbon epoxy composite materials as the Kevlar fibres when thermal damage with carbon deposition occurs.

\section{Eddy current micro-focused transducer}

The transducer is an absolute send -receiver type and has the principle scheme given in Fig. 1a and the physical realization in Fig. 1b.

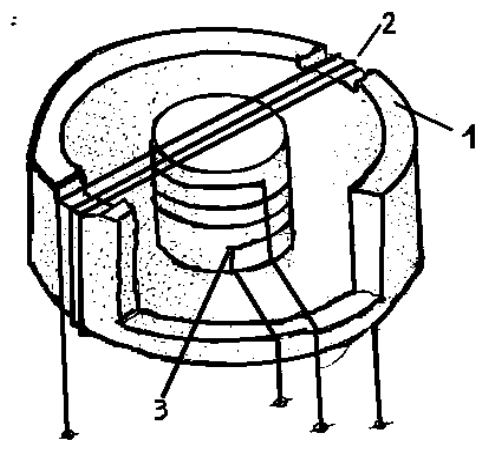

a)

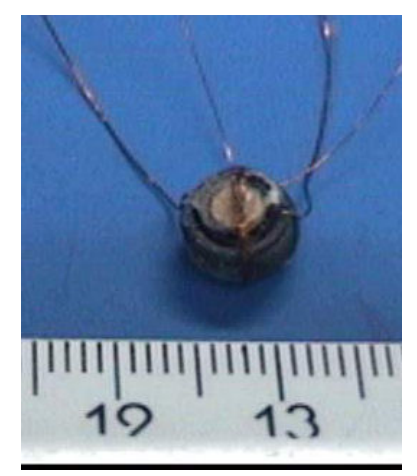

b)

Fig. 1: Eddy current focused micro transducer

a) Principle scheme: 1-ferite pot, 2 - reception coil, 3 - emission coil;

b) Physical realization.

The FERRINOX-H32 ferrite pot has the outer diameter $3.5 \mathrm{~mm}$ and a height of $2.8 \mathrm{~mm}$. The emission and reception coils have each 18 turns. At work frequency of $6 \mathrm{MHz}$, the relative magnetic permeability of ferrite pot is 12 .

To characterize the emission part of the focused transducer, a numerical simulation with finite element method was used. The calculation was made in Femlab 3.

\section{Experimental set-up}

The principle scheme of the experimental set-up is presented in Fig. 2.

The eddy current micro-focused transducer executes a scanning to examines the surface with $\mu \mathrm{m}$ step on $\mathrm{X}$ and $\mathrm{Y}$ directions. The transducer focalization on the zones that contain conductive material is made by its displacement on $\mathrm{Z}$ axis with $10 \mu \mathrm{m}$ step.

The supply of the emission part of transducer was made with function generator AWG 7223, the work frequency being $6 \mathrm{MHz}$, the amplitude of current $0.1 \mathrm{App}$. The signal delivered by the reception part is applied at input of a lock-in amplifier SR630 that allows the measurement of received signal amplitude with $0.01 \mu \mathrm{V}$ precision. The phase of signal was measured with $10^{-2}$ degree. 
A PC allows the command of manipulator and measurement instruments, the data being acquired and stored automatically.

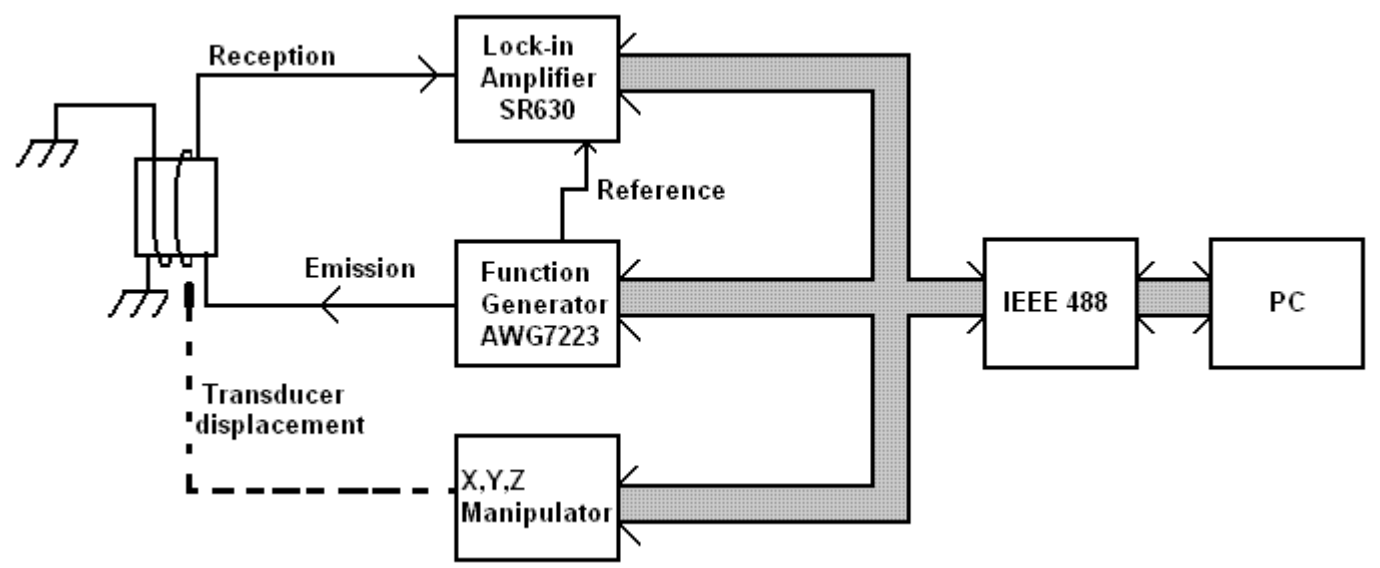

Fig. 2: Experimental set-up.

\section{The studied samples}

Hercules IM7/8551-7A composite samples that contain 16 layers of Hercules AS4 carbon fibres with average diameter $20 \mu \mathrm{m}$ with orientation $\left[-45_{2}^{0}, 0_{2}^{0}, 45_{2}^{0}\right]_{S}$ reinforced in 3502 thermosetting epoxy resin were inspected.

DuPont Kevlar texture made with MTP technology [6] contained in body armour, having 16 layers was inspected. The Kevlar texture was impacted with 7.62mm calibre bullet.

\section{Basic principle of eddy current microscopy}

In order to obtain focused images, on different fibre planes a convolution filtering procedure has been developed, taking as kernel the field scattered by a good point like scatter placed within the examined material.

Let consider that the emission part of the eddy current micro focussed transducer generates in material spherical waves with wave number $k$ and let $\bar{R}$ being the position vector of the scatter. The scattered field will be [7]

$$
\theta_{H}=c k \sin c(k R)
$$

Where $c$ is a complex constant and $R=|\bar{R}|$.

The transducer scans the surface at the constant height $z_{0}$, the scatter being located at depth $z_{1}$ below the surface, therefore the distance between transducer and scatter is $z=z_{0}+z_{1}$.

Let $\mathrm{U}\left(\mathrm{x}, \mathrm{y}, \mathrm{z}_{0}\right)$ be the signal delivered by the transducer and $\tilde{\mathrm{U}}\left(\mathrm{u}, \mathrm{v}, \mathrm{z}_{0}\right)$ its $2 \mathrm{D}$ Fourier transform, where $u$ and $v$ are spatial frequencies associated to $x$ and $y$ directions. We denote by $\tilde{\theta}(\mathrm{u}, \mathrm{v}, \mathrm{z})$ the 2D Fourier transform of the point-spread function.

The filtered and focused signal is given by the 2D Fourier transform of the convolution product of $\tilde{\mathrm{U}}\left(\mathrm{u}, \mathrm{v}, \mathrm{z}_{0}\right)$ by the kernel $\tilde{\theta}(\mathrm{u}, \mathrm{v}, \mathrm{z})$ 


$$
A(x, y, z)=\frac{1}{(2 \pi)^{2}} \int_{-\infty}^{\infty} \int_{-\infty}^{\infty} \tilde{U}\left(\mathrm{u}, \mathrm{v}, \mathrm{z}_{0}\right) \tilde{\theta}(\mathrm{u}, \mathrm{v}, \mathrm{z}) \exp j(u x+v y) d u d v
$$

The image processed in this way can be obtained with

$$
I(x, y)=|A(x, y, z)|^{2}
$$

\section{Results}

The useful information so for composite materials examination as for detection of carbon traces appeared at thermal damage of Kevlar is the phase measurements.

In Fig. 3 is presented the image delivered directly by the transducer at the scanning of $125 \times 125 \mu \mathrm{m}$ surface on composite plates. The transducer was displaced on vertical directions thus the image shall be defocused, the global image of carbon fibres being obtained.

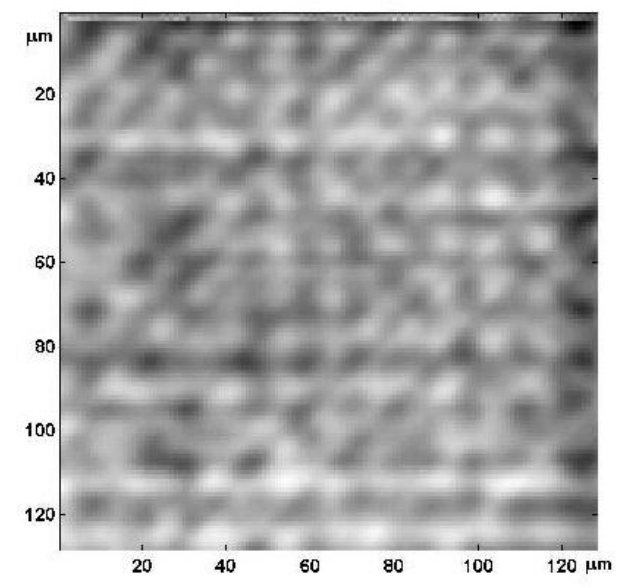

Fig. 3: Response of unfocused transducer for composite with $\left[-45_{2}^{0}, 0_{2}^{0}, 45_{2}^{0}\right]_{S}$ reinforcement.

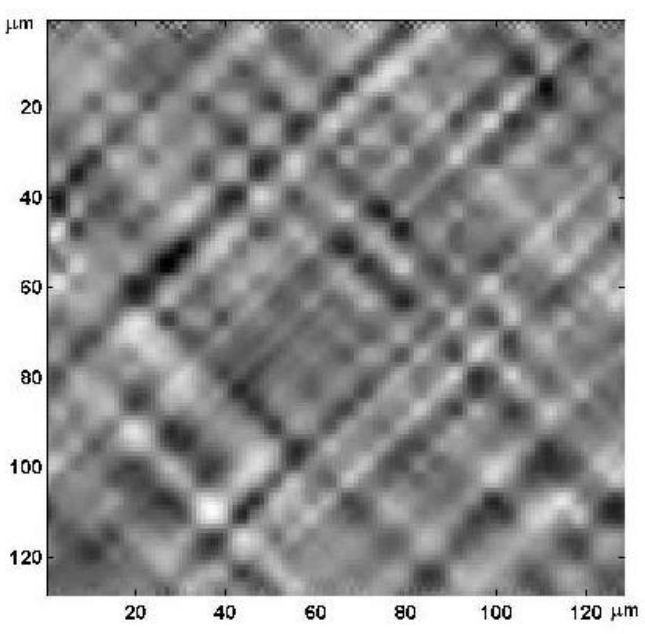

a) fibres oriented at $+45^{0}$

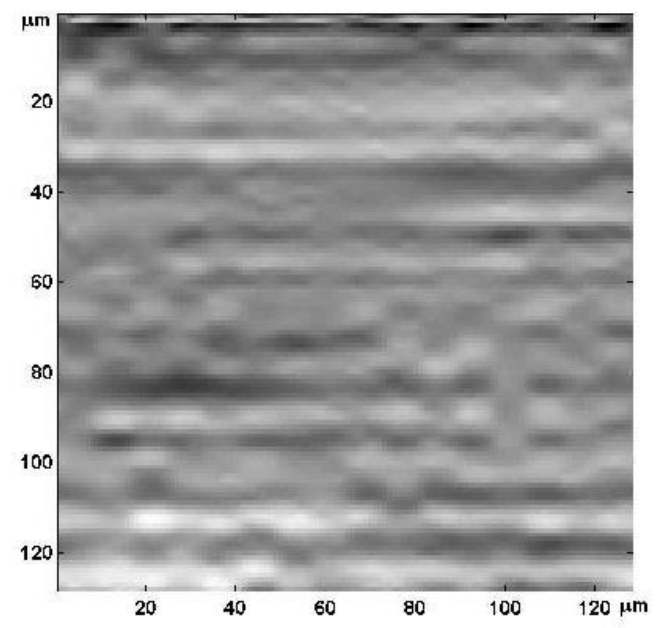

b) fibres oriented at $0^{0}$

Fig. 4: Response of focused transducer for composite with $\left[-45_{2}^{0}, 0_{2}^{0}, 45_{2}^{0}\right]_{S}$ reinforcement. 
Focusing the transducer (through its displacement on $\mathrm{z}$ direction) the image of the fibres oriented at $+45^{0}$ and those at $0^{0}$ were obtained (Fig. $4 \mathrm{a}$ and b).

In the same conditions, impacted Kevlar textures, that at microscopic examination have presented carbon traces due to thermal damage, were examined.

In Fig. 5 is presented enhanced, the picture of zone impacted with 7.62 calibre bullet.

Following the holographic method described above, applied to phase information, from the zone marked in Fig. 5, the image presented in Fig. 6 it was obtained.

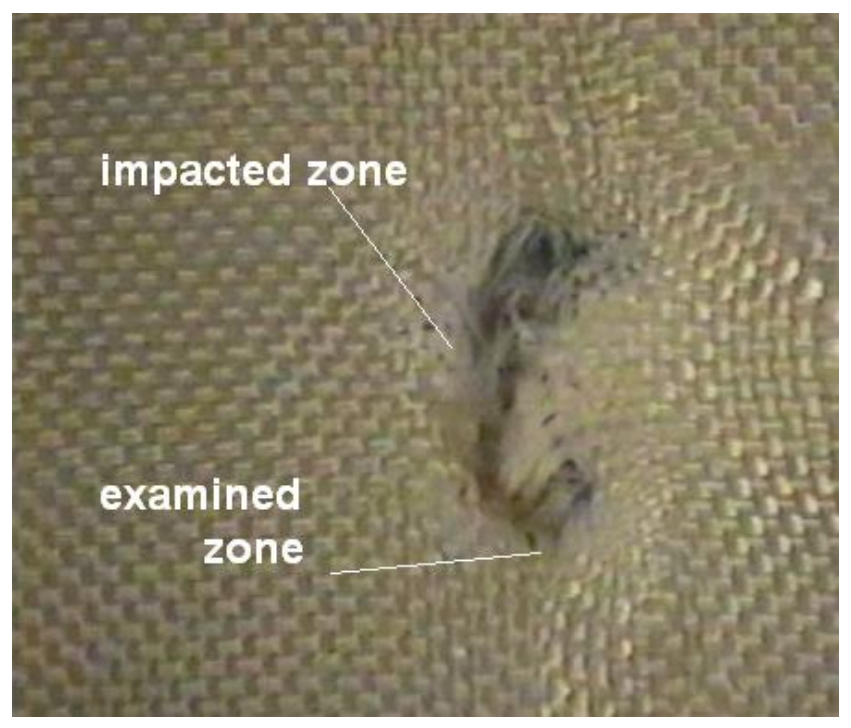

Fig. 5: Kevlar texture.

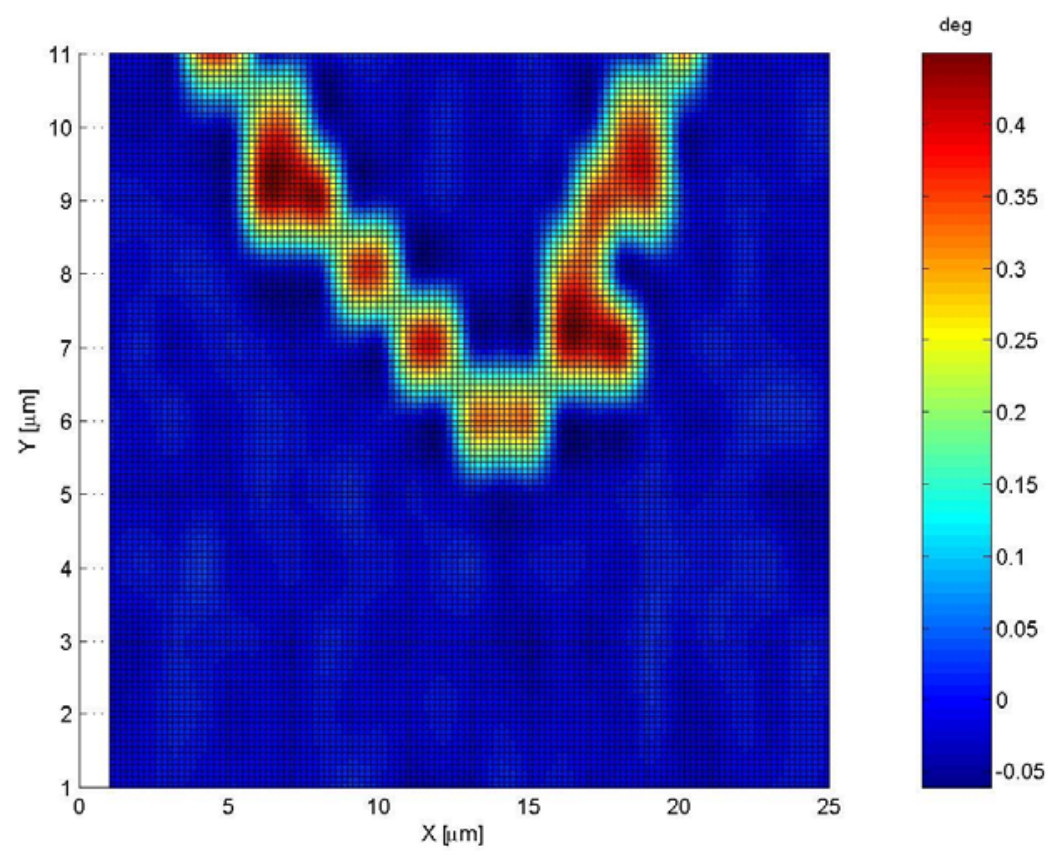

Fig. 6: Response of the transducer. 


\section{Conclusions}

The using of eddy current micro-focused transducers allows the obtaining of images of carbon fibres from carbon-epoxy composites through corresponding focussing, obtaining information about the successive fibres layers.

For the examination of Kevlar texture, insulating material from electric point of view, we have used the property of thermal damage of the fibres in the case of high energy impacts, locating the region in which free carbon has appeared.

Using the phase information that contain maximum of information, as well as the method of eddy current holography, a quality control can be made, so for carbon-epoxy composite, so for impacted Kevlar textures.

\section{Acknowledgments}

This paper is supported by Romanian Ministry of Education and Research under CNCSIS Grant no. 982.

\section{References}

[1] National Institute of Justice Standard - 0101.04 for Ballistic Resistant Armour, USA.

[2] Grimberg R, Prémel D, Savin A, Le Bihan Y., Placko D., Eddy Current Holography Evaluation of Delamination in Carbon - Epoxy Composites, INSIGHT 43,4, UK,(2001), p.260-264.

[3] Grimberg R., Prémel D., Lemistre M., Balageas D., Placko D., Compared NDE of damages in graphite/epoxy composites by electromagnetic methods, Proceedings of the SPIE's, Vol.4336, Nondestructive Evaluation of Materials and Composites; V.George\&coll. Pater J.Shull Eds.(2001), 65-72.

[4] Gros X.E., Advantages and Limitation of Nondestructive Eddy Current Testing of Composites Materials: from Rotor Blades to Dashboards, Engineering Plastics, 8, 6, 410425, 1995.

[5] Toughiry M., Examination of Nondestructive Evaluation Composites Gas Cylinders, US Department of Transportation, A7621-18:CRC-CD8.1-2002.

[6] www.dupont.com/kevlar.

[7] Langenberg K.J., Fisher M., Berger M., Weinfurter G., Imaging performance of generalized holography, J.Opt.Soc.Am. , A3(3, 329-339, 2986). 